To notify the community about a colleague's death, subscribers can visit http://www.physicstoday.org/obituaries, where they can submit obituaries (up to 750 words), comments, and reminiscences. Each month recently posted material will be summarized here, in print. Select online obituaries will later appear in print.

\section{George Dionisios Dracoulis}

U uclear physicist George Dionisios Dracoulis had a vibrant and charismatic personality. As a meticulous researcher, he was known for the reliability of his results - if George had measured it, then you knew it was right. And he took his wit and wisdom outside the laboratory when he served as a respected science adviser to the Australian government. He passed away at home in Canberra, Australia, on 19 June 2014 after a short battle with cancer.

Born in Melbourne, Australia, on 19 December 1944, George pursued his undergraduate and postgraduate studies at the University of Melbourne, from which he received a $\mathrm{PhD}$ in nuclear physics in 1970. After a three-year postdoctoral research position at the University of Manchester in the UK, he returned to Australia to take a research position at the Australian National University in Canberra, where the world's largest tandem Van de Graaff heavy-ion accelerator was under construction. George played an integral, and soon leading, role in the accelerator's development and exploitation as a research facility. As head of the university's department of nuclear physics from 1992

\footnotetext{
Recently posted notices at http://www.physicstoday.org/obituaries: Jerome Lewis Duggan

4 August 1933 - 31 August 2014

Walter E. Thirring

29 April 1927 - 18 August 2014

John Paul Carrico Sr

26 June 1938 - 31 July 2014

John McKeen McKinley

2 February 1930 - 25 July 2014

Gunther Klaus Wertheim

26 February 1927 - 14 July 2014

Thomas Fields

23 October 1930 - 27 June 2014

Johan de Swart

31 January 1931 - 10 June 2014

Nina Byers

19 January 1930 - 5 June 2014

Frank H. Low

1928 - 13 March 2014

Dwight L. Parry

3 June 1933 - 20 January 2014
}

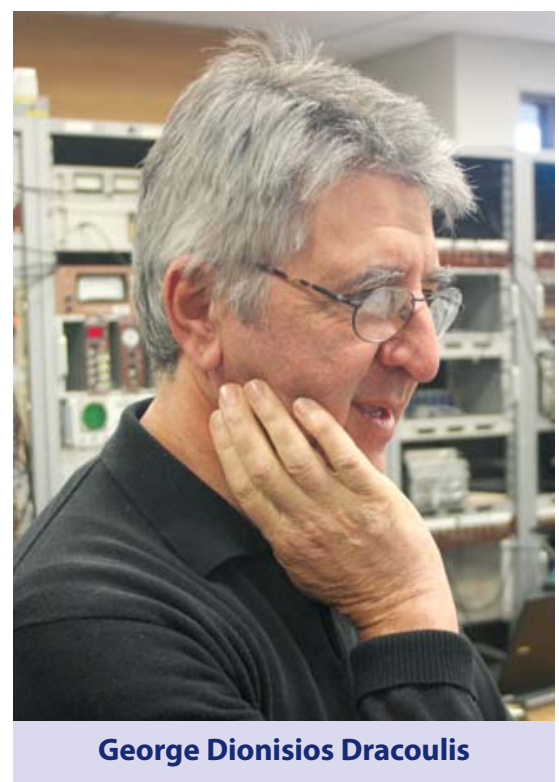

until his retirement in 2009, he established it as one of the most respected nuclear-physics laboratories in the world.

In retirement, George continued as an indefatigable researcher. He traveled the world to perform experiments and speak at conferences until diagnosed with kidney cancer in March of this year. In addition to having a network of friends and colleagues around the globe, George enjoyed extended visits to Stony Brook University in New York, Argonne National Laboratory in Illinois, Lawrence Berkeley National Laboratory in California, and the University of Surrey in the UK.

George made seminal contributions to the understanding of nuclear structure: the way different nuclear shapes can coexist; the way nuclear vibrations, especially octupole vibrations, can couple to neutron and proton excitations; and the way metastable excited states, or isomers, can be used to probe nuclear spin and shape properties. He was renowned for the thoroughness of his experimental approach, which he combined with a deep physical understanding of nuclear phenomena.

Among the numerous awards George received were the Australian Academy of Science's 2003 Thomas Ranken Lyle Medal for outstanding contributions to our understanding of the structure of atomic nuclei and the Australian Institute of Physics' 2004 Walter Boas Medal for excellence in physics research.

George served as a member of the Australian Prime Minister's Select Task Force on Uranium Mining, Processing and Nuclear Energy in 2006. As professor emeritus, he remained active in public education and continued to engage with the media and in the public discussion of nuclear energy and nuclear technology. George also continued his nuclear-physics research work until only a few weeks before he died.

George will be greatly missed by his family, friends, and colleagues around the world.

Philip Walker
University of Surrey
Guildford, UK
Andrew Stuchbery
Australian National University
Canberra
Filip Kondev
Argonne National Laboratory
Argonne, Illinois

\section{Ivan Paul Kaminow}

Van Paul Kaminow, a luminary in the photonics community, passed away in San Francisco on 18 December 2013 For more than 50 years he had been at the forefront of light-wave-technology research that helped bring about a telecommunications revolution. His contributions are evident in the ongoing activities done by the researchers, engineers, and companies working in the field.

Born on 3 March 1930 in Union City, New Jersey, Ivan received his BS in electrical engineering from Union College in 1952. After earning his MS, also in engineering, from UCLA in 1954, he began a 42-year career at Bell Labs. He earned a PhD from Harvard University in 1960; his thesis, under C. Lester Hogan and later R. Victor Jones, was on ferromagnetic resonance at microwave frequencies and high pressures.

Perhaps Ivan's greatest technical legacy from his tenure at Bell Labs is the electro-optic modulator and its materials. His contributions also included creating titanium-diffused lithium niobate modulators and other integrated optics, developing birefringent optical fibers, analyzing Raman scattering in ferroelectrics, and demonstrating such semiconductor laser technologies as the distributed Bragg reflector and the ridge waveguide. Beginning in 1984 Ivan led the photonic networks and components 